\title{
O CONCEITO DE EXPERIÊNCIA EM MICHEL FOUCAULT
}

\author{
Maximiliano Valerio López ${ }^{1}$
}

\section{Resumo}

O conceito de experiência se apresenta, na obra de Foucault, como uma constelação integrada por três problemáticas intimamente vinculadas entre si: os jogos de verdade, as relações de poder e as formas de subjetividade às quais estes jogos dão lugar. Estes elementos são veiculados a través de dispositivos heterogêneos (proposições científicas, procedimentos administrativos, estruturas arquitetônicas, etc.) que abarcam tanto o âmbito do dito como do não dito. Tais dispositivos configuram uma "experiência histórica" singular, na qual o ser (o sujeito) se pensa a si próprio e se toma como objeto de ação moral. No entanto, toda a obra do autor está perpassada por uma tensão entre a possibilidade de, por meio de minuciosos estudos históricos, estabelecer os limites dessa experiência histórica, e um exercício propriamente filosófico a través do qual se tenta fazer experiência do próprio limite, quer dizer, realizar uma experiência trágica capaz de colocar em entredito a própria experiência e as formas de subjetividade à qual ela está ligada.

Palavras-chave: Experiência Histórica; Experiência Trágica; Poder; Saber, Subjetividade; Dispositivo.

\section{O conceito de experiência}

\footnotetext{
${ }^{1}$ Mr. Maximiliano Valerio López. Rua Pachual Carlos Magno 103, apartamento 401. Santa Teresa. Rio de Janeiro. Tel. (55-21) 2507-4705. Endereço eletrônico: maxlop@ hotmail.com maximilianolopez@vm.uff.br Professor em Ciencias de la Educación pela Universidad Nacional de Cuyo (Argentina); Especialista em Ensino da Filosofia pela Universidade de Brasília (UNB); Mestre em Educação pela Universidade do Estado do Rio de Janeiro (UERJ) Doutorando em Educação pela Universidade do Estado do Rio de Janeiro. Vinculo empregatício atual: Professor assistente na Universidade Federal Fluminense (UFF).
} 
Segundo uma afirmação, cada vez mais familiar no âmbito da filosofia, esta consistiria na criação de conceitos. Esses conceitos seriam espécies de nós ou pontos de condensação do pensamento de cada filósofo. Pois bem, gostaria de sustentar aqui que há um conceito de experiência que leva a assinatura de Michel Foucault.

Digamos junto com Gilles Deleuze e Felix Guattari que "não há conceitos simples”, que "cada conceito tem componentes que podem, por sua vez, ser tomados como conceitos" e que, por outro lado, "é próprio do conceito tornar os componentes inseparáveis nele: distintos, heterogêneos e, todavia, não separáveis....” (DELEUZE; GUATTARI, 1992, p. 27-31). Cada conceito se nos apresenta então como um composto heterogêneo e indivisível, um arquipélago ou uma constelação, e se define, precisamente, pela sua consistência, quer dizer, pela relação intrínseca que esses elementos estabelecem entre eles. Assim, para compreender o conceito de experiência, no horizonte do pensamento de Michel Foucault, devemos considerar os elementos que o compõem e a relação que entre eles se estabelece.

Com frequência acostuma-se organizar a obra de Michel Foucault em torno a três eixos ou tópicos principais: o saber (a análise do discurso, a experiência literária, a arqueologia dos sistemas de pensamento, a episteme, etc.), o poder (a genealogia dos dispositivos de controle social, os sistemas disciplinares, o panóptico, etc.) e a subjetividade (os estudos acerca da maneira em que os sujeitos são levados a se colocar, diante de si mesmos, como objetos de saber e ação moral: os exercícios espirituais, as artes da existência, etc.). Esses três domínios delimitariam também três períodos na sua obra: o primeiro, ligado ao saber, se desenvolve aproximadamente desde a publicação de sua primeira grande obra História da loucura (1961) até a publicação de A arqueologia do saber (1969), neste período estariam também incluídas trabalhos como $O$ nascimento da Clínica (1963) e As palavras e as coisas (1966); o segundo período, ligado à questão do poder, estender-se-ia desde princípios dos anos 70 até 1976 e incluiria Vigiar e punir (1975) e o primeiro volume da Historia da sexualidade, intitulado, A vontade de saber (1976); o terceiro e último período, ligado a subjetividade, compreenderia o segundo e terceiro volume da História da sexualidade, intitulados, respectivamente, $O$ uso dos prazeres e $O$ cuidado de si, ambos de 1984. Embora essa classificação tenha um 
indiscutível valor didático acaba muitas vezes dando a impressão de que, na obra de Foucault, um domínio vá substituindo outro, assim como, a nível metodológico, o método genealógico substituindo o método arqueológico. Mas, se levarmos em consideração a análise retrospectiva que o próprio Foucault lança sobre a sua obra nos últimos anos, parece mais adequado compreender estes deslocamentos temáticos e metodológicos como dimensões de um mesmo e único projeto.

Numa entrevista com Hubert Dreyfus e Paul Rabinow, de 1983, o autor declara:

Eu gostaria de dizer, antes de mais nada, qual foi o objetivo de meu trabalho nos últimos vinte anos. Não foi analisar o fenômeno do poder nem elaborar os fundamentos de tal análise. Meu objetivo, ao contrario, foi criar uma história dos diferentes modos pelos quais, em nossa cultura, os seres humanos tornaram-se sujeitos. Meu trabalho lidou com três modos de objetivação que transformam os seres humanos em sujeitos. O primeiro é o modo da investigação, que intenta atingir o estatuto de ciência, como, por exemplo, a objetivação do sujeito do discurso na gramaire générale, na filologia e na lingüística. Ou, ainda, a objetivação do sujeito produtivo, do sujeito que trabalha, na análise das riqueza e da economia. $\mathrm{Ou}$, um terceiro exemplo, na objetivação do simples fato de estar vivo na história natural e na biologia. Na segunda parte de meu trabalho, estudei a objetivação do sujeito naquilo que eu chamarei de 'práticas divisoras'. O sujeito é dividido no seu interior e em relação aos outros. Este processo o objetiva. Exemplos: o louco e o são, o doente e o sadio, os criminosos e os 'bons meninos'. Finalmente, tentei estudar -meu trabalho atual- o modo pelo qual um ser humano torna-se um sujeito. Por exemplo: eu escolhi o domínio da sexualidade -como os homes aprendem a se reconhecer como sujeitos de 'sexualidade'. Assim, não é o poder, mas o sujeito, que constitui o tema geral de minha pesquisa. (DREYFUS; RABINOW, 1995, p. 231-232).

É no interior desta perspectiva mais abrangente que devemos situar a análise do conceito foucaultiano de experiência. Se cada conceito está composto por elementos, que por sua vez podem ser tomados como conceitos, digamos então, que os três motivos em questão (o saber, o poder e a subjetividade) podem ser considerados elementos do conceito de experiência.

É importante destacar também que todo conceito remete a um problema sem o qual careceria de sentido e que, ao mesmo tempo, um problema só se torna perceptível em função do conceito que o faz emergir. Existe uma solidariedade íntima entre conceito e problema. Digamos por tanto, que se o conceito de experiência se define estruturalmente em relação aos conceitos de saber, poder e subjetividade, o problema ao qual eles se vinculam é formulado por Foucault na citação que acabamos de ler da seguinte maneira: 
"entender os diferentes modos pelos quais, em nossa cultura, os seres humanos tornaram-se sujeitos" (DREYFUS; RABINOW, 1995, p. 231-232).

Na introdução de $O$ uso dos prazeres (segundo volume da História da sexualidade), publicado um ano após a mencionada entrevista, o autor volta mais uma vez sobre suas pegadas para dar conta das peripécias de seu projeto mais recente. Uma série de problemas tinha atrasado oito anos a publicação do livro e é destas dificuldades, e das mudanças que acarretaram, de que fala na introdução. A história que me propunha escrever, diz o autor, não pretendia ser nem uma história dos comportamentos nem uma história das representações, mas "uma historia da sexualidade como experiência" (FOUCAULT, 1984, p. 10-11).

Tratava-se de ver de que maneira, nas sociedades ocidentais modernas, constituiu-se uma 'experiência' ${ }^{2}$ tal, que os indivíduos são levados a reconhecerse como sujeitos de uma 'sexualidade' que abre para campos de conhecimento bastante diversos, e que se articulada em um sistema de regras e coerções. $\mathrm{O}$ projeto era, portanto, o de uma história da sexualidade enquanto experiência, se entendemos por experiência a correlação, em uma cultura, entre campos de saber, tipos de normatividade e formas de subjetividade. [...] Falar da 'sexualidade' como uma experiência historicamente singular suporia, também, que pudesse dispor de instrumentos suscetíveis de analisar, em seu próprio caráter e em suas correlações, os três eixos que a constituem: a formação dos saberes que a ela se referem, os sistemas de poder que regulam sua prática e as formas pelas quais os indivíduos podem e devem se reconhecer como sujeitos dessa sexualidade. (FOUCAULT, 1984, p. 10-11).

Deste modo Foucault evoca o conceito de experiência para dar conta da correlação, dentro de uma cultura, entre os três eixos já mencionados: o saber, o poder e a subjetividade. A experiência histórica (neste caso, da sexualidade) não é outra coisa que a trama de discursos e práticas por meio dos quais se dá forma àquilo que somos. É essa trama a que constitui nossa experiência possível em cada lugar e cada momento. A experiência não é aqui a experiência em geral, mas a experiência concreta, histórica e culturalmente situada. Não se trata de determinar as condições de possibilidade da experiência humana, colocando como apriori um sujeito transcendental ou universal, senão de tornar visíveis as condições concretas que tem permitido a conformação de um particular tipo de experiência. É precisamente essa experiência histórica a que cria o sujeito, não um

\footnotetext{
${ }^{2}$ As aspas se encontram no original.
}

Revista Reflexão e Ação, Santa Cruz do Sul, v.19, n2, p.42-55, jul./dez. 2011 
sujeito universal, mas uma singular forma de sujeito: uma subjetividade. Não há primeiro um sujeito transcendental, a partir do qual possam se explicar as condições de possibilidade da experiência, ao contrário, é a experiência histórica a que explica a emergência de um tipo particular de subjetividade. Não se trata então de descobrir a verdade a partir do sujeito, mas de estudar, os jogos de verdade e as práticas concretas com base nas quais o sujeito se constitui historicamente. Os estudos foucaultianos nos falam de um particular uso da história:

Uma história que não seria aquela do que poderia haver de verdadeiro nos conhecimentos; mas uma análise dos 'jogos de verdade', dos jogos entre o verdadeiro e o falso, através dos quais o ser se constitui historicamente como experiência, isto é, como podendo e devendo ser pensado. (FOUCAULT, 1984, p. 13).

\section{Uma ontologia do presente: a questão da Aufklärung}

Poder-se-ia dizer que Foucault trousse para o interior da filosofia um olhar etnográfico, como aquele que Lévi-Strauss e outros antropólogos contemporâneos tinham desenvolvido em relação a culturas alheias. A filosofia de Michel Foucault é, em certo sentido, uma etnografia da própria cultura européia, o que pressupõe olhar a própria tradição como se ela fosse estranha, tentando escapar de todos aqueles aprioris antropológicos e de todos aqueles universalismos característicos do etnocentrismo europeu; aquele mesmo etnocentrismo que substancializou os traços contingentes de sua própria tradição. É nesse sentido, que Foucault contrapõe a "analítica da verdade" própria da filosofia tradicional, àquilo que ele denomina uma "ontologia histórica do presente", no intuito de desenvolver uma filosofia da cultura refratária a qualquer pretensão de universalidade. É precisamente desde essa perspectiva que irá recuperar, a sua maneira, a famosa interrogação que em 1784 lançara o filósofo alemão Immanuel Kant: Was heisst Aufklärung? [o que é a ilustração?], ou seja, o que nos acontece hoje, nesse preciso momento da história? Ou, nos termos de Foucault: quem somos nós, hoje? Não quem somos nós em geral (universalmente), mas quem somos nós, agora, neste singular momento histórico, e no interior das fronteiras desta experiência cultural que é a nossa? 
Trata-se de fazer a historia da constituição da "experiência de si" dos povos europeus, com todas as suas contingências culturais e históricas, recusando qualquer idéia de origem transcendental ou divina, qualquer privilegio em relação a outras tradições, estudando a contingência histórica de aquilo que aparece na tradição européia como universal e necessário. Estudando a maneira como o ser humano tem sido levado em ocidente, a se experimentar a si próprio no interior de uma série de jogos de verdade e de relações de força. Em outras palavras, tentará fazer uma historia da "experiência de si" e seus acidentes.

Por isso o problema não será tanto a verdade ou a falsidade, num sentido genérico, quanto as condições estratégicas nas quais uma verdade tem se tornado possível e operante, adquirindo a capacidade de modelar a vida e os afetos. Por isso não se tratará de interrogar a verdade em si mesma, mas o valor, o efeito e o sentido estratégico dessas verdades num determinado momento, questionando, ao mesmo tempo, as práticas que a ela estão vinculadas.

\section{Experiência e dispositivo}

O conceito de "experiência" se encontra intimamente vinculado ao conceito de “dispositivo". Como disse no principio é comum distinguir em Foucault um período arqueológico, ligado a descrição das epistemes, e um período genealógico, ligado a descrição dos dispositivos. Poder-se-ia afirmar, como o faz Edgardo Castro (CASTRO, 2004, p.98) que a episteme é, nesse sentido, um caso particular de dispositivo. O dispositivo é um conjunto heterogêneo de discursos, instituiçõos, estruturas arquitetônicas, decisões regulamentares, leis, medidas administrativas, enunciados científicos, proposições filosóficas, morais e filantrópicas, em resumo: tanto o dito como o não dito. O dispositivo é a rede que se estabelece entre estes elementos, tem uma função estratégica e está sempre inscrito num jogo de poder e, ao mesmo tempo, sempre ligado aos limites do saber, que derivam desse e, na mesma medida, condicionam-no. Assim, o dispositivo é: um conjunto de estratégias de relações de força que condicionam certo tipo de saber e por ele são condicionados. Como se vê o dispositivo tem um sentido muito próximo ao que, no prólogo 
de $O$ uso dos prazeres Foucault dá ao conceito de experiência, ou seja, assinala o entrecruzamento dos mecanismos de saber e de poder que dão forma à experiência de si.

Em 2005, Giorgio Agamben proferiu no Brasil uma conferência publicada anos mais tarde com o título $O$ que é um dispositivo? onde oferece uma breve genealogia do conceito de dispositivo. No final dos anos sessenta, assinala o filósofo italiano, Foucault não utiliza ainda, o termo dispositivo para definir seu objeto de pesquisa, em seu lugar emprega o termo positivité, etimologicamente muito próximo. Agamben confessa ter-se perguntado muitas vezes de onde Foucault poderia ter tirado esse termo, até que, releu um ensaio de Jean Hyppolite intitulado Introdution à La philosophie de l'histoire de Hegel ${ }^{3}$. No terceiro capítulo, que leva o título de Raison et histoire. Les idées de positivité et destin, Hyppolite analisa uma obra de Hegel titulada A positividade da religião cristã [Die Positivitat des chistliche Religion] e comenta que nela o termo "dispositivo" encontra seu lugar próprio na oposição entre "religião natural" e "religião positiva": enquanto a religião natural diz respeito à imediata e geral relação da razão humana com o divino, a religião positiva ou histórica compreende o conjunto das crenças, das regras e dos ritos que numa determinada sociedade e num determinado momento histórico são impostos aos indivíduos pelo exterior. "Uma religião positiva", escreve Hegel, numa passagem que Hyppolite cita, “implica sentimentos que vêm impressos nas almas por meio de uma coerção e comportamentos que são o resultado de uma relação de comando e obediência e que são cumpridos sem um interesse direto". (HYPPOLITE, 1983, p. 43. Apud AGAMBEN, 2009, p. 30-31). A oposição entre natureza e positividade corresponde, nesse sentido, à dialética entre liberdade e coerção e entre razão e história. "Positividade" é, segundo Hyppolite, o nome que Hegel dá ao elemento histórico, com toda sua carga de regras, ritos e instituições impostas aos indivíduos por um poder externo, mas que se torna, por assim dizer, interiorizada nos sistemas das crenças e dos sentimentos. Na opinião de Agamben, Foucault toma emprestado então este termo (que se tornará mais tarde "dispositivo"), para pensar um problema decisivo, que é também o seu problema mais próprio: a relação entre os indivíduos como seres viventes e o elemento histórico, entendendo com este termo o

\footnotetext{
${ }^{3}$ E importante lembrar a forte relação que vinculava Foucault e seu mestre Hyppolite, quem fora seu professor no liceu Henri IV e depois na École Normale.
}

Revista Reflexão e Ação, Santa Cruz do Sul, v.19, n2, p.42-55, jul./dez. 2011 
conjunto das instituições, dos processos de subjetivação e das regras em que se concretizam as relações de poder. O objetivo último de Foucault, esclarece Agamben, não é, porém, como em Hegel, reconciliar os dois elementos nem mesmo enfatizar o conflito entre eles. Trata-se antes, para ele, de investigar os modos concretos em que as positividades (ou os dispositivos) agem nas relações, nos mecanismos e nos jogos de poder (AGAMBEN, 2009, p. 32-33).

Quando Foucault se pergunta, como os seres humanos se tornaram (historicamente) sujeitos, o que tenta destacar é a maneira como os corpos sensíveis foram capturados, subjetivados, moldados a partir de uma série de discursos, instituições, estruturas arquitetônicas, leis, medidas administrativas, enunciados científicos, proposições filosóficas, morais e filantrópicas, etc. Em outras palavras, como a partir de estes “dispositivos", foi possível uma determinada "experiência de si” e do outro.

A novidade que aporta a perspectiva foucaultiana do poder em relação a análises anteriores (como a de Hegel, por exemplo) reside em que, no seu caso, os dispositivos não se apresentam como contrários à liberdade. Eles capturam, conduzem e governam as almas sem transformar os sujeitos, porém, em meros alvos de um poder repressivo. Dai que todo dispositivo implica um processo de subjetivação, sem o qual não atuaria como dispositivo de governo, mas como mera coação externa. Como fica exposto em Vigiar e punir, por exemplo, numa sociedade disciplinar os dispositivos visam a criação de corpos dóceis e produtivos, mas livres. Quer dizer, corpos que assumem a sua liberdade e a sua identidade de sujeitos no próprio processo de seu assujeitamento.

Os dispositivos não são contrários à liberdade, nem um acidente produto do azar ou a maldade humana, mas a maneira pela qual os corpos se tornam sujeitos. Sempre sujeitos históricos e espacialmente situados, mas também, sempre sujeitos assujeitados. Por traz do dispositivo foucaultiano não está o sujeito livre e autônomo, o sujeito esclarecido e universal que a tradição européia imaginou. O que há então para além dos dispositivos? O que há para além da experiência histórica que os dispositivos conformam?

\section{O contra-dispositivo ou a experiência trágica}


A resposta a esta interrogação pulsa já nos primeiros escritos de Foucault, o que reforça a hipótese de que na sua obra os assuntos não se ordenam numa sucessão cronológica simples, mas se integram e se dobram, uns sobre outros, numa composição densa e integrada.

Os dispositivos de captura, nos quais os seres humanos são, ao mesmo tempo, objetivados e subjetivados, dependem em grande medida do que Foucault chamou de pratiques divisantes [práticas divisoras] por meio das quais ocidente cria uma cisão entre o que considera o próprio (aquilo que lhe dá sua identidade e sua continuidade histórica) e o alheio. Assim aparece o louco como o oposto do sujeito de razão, os anormais como opostos ao cidadão integrado, mas também toda uma gama de alteridades perante as quais o sujeito europeu se constitui como uma identidade (o oriente, o homossexual, o selvagem, etc.). Essa cisão, esse traçado de limites, essa criação de fronteiras, diz Foucault, definem ao sujeito ocidental, tanto ou mais, que seus valores. Porque, enquanto os valores cada sociedade os recebe da sua tradição cultural, na continuidade da história, esses gestos de divisão são como o nascimento mesmo de sua história. Pois a história, como corrente de causas e efeitos, só faz sentido após a divisão.

É em direção a esse gesto silencioso, que no interior de uma cultura define a identidade e a alteridade, que Foucault endereça sua pesquisa.

Em direção a que poderia então conduzir-nos uma interrogação que não seguiria a razão em seu devir horizontal, mas buscaria retraçar no tempo essa verticalidade constante que, ao longo da cultura européia, a confronta com o que ela não é, medindo-a em sua própria desmedida? [...] Uma região, sem dúvida, onde se trata mais dos limites do que da identidade de uma cultura. [...] Interrogar uma cultura sobre suas experiências-limites é questioná-la, nos confins da história, sobre um dilaceramento que é como o nascimento mesmo da sua história. Então, encontram-se confrontados, em uma tensão sempre prestes a desenlaçar-se, a continuidade temporal de uma analise dialética e o surgimento, ás portas do tempo, de uma estrutura trágica. (FOUCAULT, 1999, p. 142).

Confrontam-se então duas análises possíveis: por um lado um tipo de análise que Foucault chama dialética, análise horizontal, que visa reconstruir os encadeamentos causais que explicam o surgimento do real. Nesta dimensão encontraríamos a historia interna, por assim dizer, do pensamento. Por outro lado, encontraríamos o que ele denomina de uma análise trágica, análise vertical, que confrontaria a razão e o discurso com um fundo sem 
sentido, um murmúrio delirante que percorreria a história por baixo, quase imperceptivelmente. Na análise dialética trata-se de estabelecer, no plano do sentido, as relações que vinculam as proposições entre si (logicamente) e os fatos entre si (empiricamente) e, também, o vínculo entre essas proposições e esses fatos. Mas, na análise trágica se busca compreender a relação entre os discursos e esse fundo sem sentido que, sendo palavra ainda não é discurso, tendo acontecido ainda não é história; esse fundo que ameaça uma vez por outra desmoronar as pilastras de toda a obra da razão e da história.

Para contextualizar o referido contraste entre uma experiência histórica e uma experiência trágica tenho que me referir, brevemente, ao problema do trágico, que dominou a cena durante o século XIX na Alemanha e que pela mão de Friedrich Nietzsche, é introduzido depois no cenário francês dos anos sessenta. Como assinala Roberto Machado em seu livro O nascimento do trágico (MACHADO, 2006), há que distinguir o trágico, enquanto problema filosófico, dos estudos poetológicos sobre a tragédia grega. Estes últimos procedem da antiguidade e tem na Poética de Aristóteles sua referencia principal. O trágico, ao contrário, é um problema filosófico surgido entre fines do século XVIII e princípios do XIX, na Alemanha, a partir da reinterpretação ontológica que poetas/filósofos alemães fizeram da tragédia grega à luz do pensamento kantiano; sobre tudo no que diz respeito a sua distinção entre o sentimento do belo e do sublime. Essa releitura ontológica consiste em ver na tragédia ática um exemplo paradigmático da condição humana, a qual estaria sempre tensionada entre duas dimensões antagônicas: uma ligada às formas (necessariamente limitadas) e outra ao aórgico e ilimitado.

Segundo o refere Kant (1990) na sua Crítica do juízo, o sentimento do belo se experimenta fundamentalmente como uma sensação de calma é tranqüilidade na contemplação de objetos que possuem formas definidas quando o entendimento e a imaginação (as duas faculdades que compõem a razão) podem se exercer de forma coordenada e harmoniosa. O sentimento sublime, ao contrário, se experimenta como um sentimento contraditório, mistura de dor e prazer, de atração e repulsa, nas ocasiões em que a mente se depara com um espetáculo desmesurado, carente de contornos e limites definidos. Nestes últimos casos, a imaginação, por não encontrar limites, não pode se exercer e claudica, no entanto o entendimento continua a operar, de modo que, esta 
particular situação, em que se pode compreender sem, contudo, conseguir imaginar, produz o desencontro das faculdades e o sentimento contraditório. A partir desta distinção kantiana, Schiller conceberá a tragédia grega como uma espécie de dispositivo capaz de apresentar de forma sensível o supra-sensível, ou seja, capaz de representar o irrepresentável ou como uma forma capaz de apresentar numa forma finita o absoluto. A tragédia passará então a constituir para ele, e para os pensadores românticos que continuam a se debruçar sobre este assunto, uma maneira privilegiada de representar o drama constitutivo da existência humana, a tensão permanente entre o finito e o infinito.

Os seres humanos, só conseguem perceber e representar formas, mas estas formas emergem sempre por diferenciação de um fundo ilimitado e a ele podem voltar a qualquer momento. Este fundo é o que não podemos pensar nem ordenar à maneira de um sistema. Este fundo é o absolutamente outro, o que se furta a nosso saber e a nosso poder e, por isso mesmo, ameaça-nos constantemente. Nossa identidade pessoal, nossa subjetividade (para usar um termo foucaultiano) flutua, como o refere Nietzsche em A origem da tragédia, sobre um mar desatado que levanta e abate montanha de ondas cheias de espuma. Nossa subjetividade não é mais do que uma forma sempre preste a se desmanchar no infinito. Assim, dirá Foucault, no prólogo da História da loucura (FOUCAULT, 1999, p. 140-148), a obra da razão (as formas de contornos nítidos que Nietzsche chamava de apolíneas) é sempre ameaçada por um rumor surdo que percorre o tempo na forma de delírio (de canto dionisíaco, na linguagem nietzscheana). A modernidade erigiu um muro para se proteger desse fundo indiferenciado e o chamou de "doença mental", mas o que aterra da loucura e que, em definitiva, sabemos que ela não é uma anomalia, mas o fundo infinito (o semfundo) no qual se abisma toda obra da razão.

A arte trágica não é outra coisa que a experiência desse abismo, uma experiência capaz de colocar em questão a própria identidade. Se a experiência histórica, e os dispositivos que lhe dão forma, produzem no seu exercício uma subjetividade, a experiência trágica atua como um contra-dispositivo de dessubjetivação, um poder capaz de liberar o sujeito da sua própria identidade e das amarras que ela traz consigo. Compreendese então por que, naquela entrevista com Dreyfus e Rabinow com a que iniciamos este trabalho, Foucault pode dizer

Revista Reflexão e Ação, Santa Cruz do Sul, v.19, n2, p.42-55, jul./dez. 2011 
Talvez, o objetivo hoje não seja descobrir o que somos, mas recusar o que somos. Temos que imaginar e construir o que poderíamos ser para nos livrarmos deste 'duplo constrangimento' político, que é a simultânea individualização e totalização própria às estruturas do poder moderno. A conclusão seria que o problema político, ético, social e filosófico de nossos dias não consiste em tentar liberar o individuo do Estado nem das instituições do Estado, porém nos liberarmos tanto do Estado quanto do tipo de individualização que a ele se liga. Temos que promover novas formas de subjetividade a través da recusa deste tipo de individualidade que nos foi imposta há vários séculos. (DREYFUS; RABINOW, 1995, p. 239).

Se por uma parte os estudos foucaultianos se endereçam, por meio de um trabalho genealógico, a traçar os "limites da experiência" de si (limites históricos e culturais), por outra parte, é possível reconhecer no trabalho da filosofia o que poderíamos denominar uma "experiência do limite" ou, em outras palavras, uma experiência trágica. Essa tensão entre um estudo histórico dos limites da experiência e um exercício filosófico que se constitui como experiência do limite, percorre toda sua obra. No prólogo de $O$ uso dos prazeres, podemos ler nesse sentido:

Os estudos que se seguem, assim como outros que anteriormente empreendi, são estudos de 'história' pelos campos que tratam e pelas referências que assumem; mas não são trabalhos de 'historiador'. O que não quer dizer que eles resumam ou sintetizem o trabalho feito por outros; eles são - se quisermos encará-los do ponto de vista de sua 'pragmática' - o protocolo de um exercício que foi longo, hesitante, e que freqüentemente precisou se retomar e se corrigir. Um exercício filosófico: sua articulação foi a de saber em que medida o trabalho de pensar sua própria história pode liberar o pensamento daquilo que pensa silenciosamente, e permitir-lhe pensar diferentemente. (FOUCAULT, 1984, p. 16).

A verdade e a liberdade que Foucault parece praticar não possuem um conteúdo específico. A experiência trágica, capaz de colocar em questão os limites da experiência histórica e suspender os dispositivos no interior dos quis temos chegado a ser o que somos, não é uma experiência de algo, mas uma experiência da própria experiência. Uma experiência de nosso ser histórico e político, uma experiência da contingência da própria experiência de si.

\section{EL CONCEPTO DE EXPERIENCIA EN MICHEL FOUCAULT}




\section{Resumen}

El concepto de experiencia se presenta, en la obra de Foucault, como una constelación integrada por tres problemáticas íntimamente vinculadas entre sí: los juegos de verdad, las relaciones de poder e las formas de subjetividad a las cuales estos juegos dan lugar. Estos elementos son vehiculados a través de dispositivos heterogéneos (proposiciones científicas, procedimientos administrativos, estructuras arquitectónicas, etc.) que abarcan tanto el ámbito de lo dicho como el de lo no dicho. Tales dispositivos configuran una "experiencia histórica" singular, en la que el ser (el sujeto) se piensa a sí mismo e se toma como objeto de acción moral. Sin embargo, toda la obra del autor está atravesada por una tención entre, la posibilidad de, por medio de minuciosos estudios históricos, establecer los límites de esa experiencia histórica, y un ejercicio propiamente filosófico a través del cual se intenta hacer experiencia del propio límite, es decir, realizar una experiencia trágica capaz de colocar en entredicho la propia experiencia y las formas de subjetividad a la que esta está ligada.

Palabras clave: Experiencia Histórica; Experiencia Trágica; Poder; Saber, Subjetividad; dispositivo.

\section{Referências}

CASTRO, E. El vocabulário de Michel Foucault. Universidad Nacional de Quilmes, 2004.

DREYFUS, H.; RABINOW, P. Michel Foucault, uma trajetória filosófica. Rio de Janeiro: Forense Universitária, 1995.

FOUCAULT, M. Problematização do sujeito: psicologia, psiquiatria e psicanálise (Ditos e escritos Vol. I). Rio de Janeiro: Forense Universitária, 1999.

FOUCAULT, Michel. "A loucura, a ausência da obra". In: Ditos \& escritos I. Problematização do sujeito: psicologia, psiquiatria y psicanálise; tradução de Vera Lucia Avellar Ribeiro. Rio de Janeiro, Forense Universitária, 1999. 
FOUCAULT, Michel. "Cómo nace un 'libro-experiencia"” In: El yo minimalista y otras conversaciones. Buenos Aires: La marca, 1996.

FOUCAULT, Michel. História da Loucura na Idade Clássica. São Paulo: Perspectiva, 1978.

FOUCAULT, Michel. História da Sexualidade - A Vontade de Saber, Vol. I, RJ: Graal, 1977.

FOUCAULT, Michel. História da Sexualidade - O Uso dos Prazeres, Vol. II Rio de Janeiro: Graal, 1984.

FOUCAULT, Michel. Prefácio (Folie et déraison)". In: Ditos \& escritos I. Problematização do sujeito: psicologia, psiquiatria y psicanálise; tradução de Vera Lucia Avellar Ribeiro. Rio de Janeiro: Forense Universitária, 1999a.

FOUCAULT, Michel. Vigiar e Punir. Petrópolis: Vozes, 1977.

KANT, I. Crítica del juicio. La Habana: Editorial de Ciencias Sociales. 1990.

MACHADO, R. O nascimento do trágico: de Schiller a Nietzsche. Rio de Janeiro: Jorge Zahar, 2006.

NIETZSCHE, Friedrich. A origem da tragédia. Trad. de Álvaro Ribeiro. Lisboa: Guimarães ed., 2000.

SZONDI, P. Ensaio sobre o trágico. Rio de Janeiro: Jorge Zahar, 2004.

Data de recebimento: $15 / 10 / 2011$

Data de aceite: $21 / 11 / 2011$ 